\title{
Aging Adults and Seasonal Influenza: Does the Vitamin D Status (H)Arm the Body?
}

\author{
Pierre Olivier Lang ${ }^{1,2}$ and Dimitrios Samaras ${ }^{1}$ \\ ${ }^{1}$ Department of Internal Medicine, Rehabilitation and Geriatrics, Medical School and University Hospitals of Geneva, Hospital of \\ Trois-Chêne, Chemin du Pont-Bochet 3, CH-1226 Thônex-Geneva, Switzerland \\ ${ }^{2}$ Translational Medicine Research Group, Cranfield Health, Cranfield University, Vincent Building, College Road, \\ Cranfield MK430AL, UK
}

Correspondence should be addressed to Pierre Olivier Lang, pierre.o.lang@hcuge.ch

Received 23 June 2011; Accepted 23 August 2011

Academic Editor: Monika Neuhäuser-Berthold

Copyright ( $) 2012$ P. O. Lang and D. Samaras. This is an open access article distributed under the Creative Commons Attribution License, which permits unrestricted use, distribution, and reproduction in any medium, provided the original work is properly cited.

\begin{abstract}
Vitamin D (VitD), although originally described as an essential hormone for bone and mineral homeostasis, appears to have an active role in regulating specific facets of human immunity. Indeed, VitD has been shown to have significant effects on cytokine production and lymphocyte proliferation. Evidence that VitD affects clearance of selected pathogens is supported by epidemiological and clinical data, while its coadministration with influenza vaccine in mice enhanced both mucosal and systemic antibody responses. This paper aims to examine how VitD may contribute to limiting the burden of influenza infection in the aging and aged adults, a population in which this burden remains considerable. Furthermore, we discuss how VitD status may play a role in host resistance to influenza virus and influence the immunogenicity of the influenza vaccines currently licensed for adults aged 65 years or over by its effects on innate and adaptive immunities.
\end{abstract}

\section{Introduction}

Worldwide, naturally occurring dietary sources of vitamin D (VitD) are limited, and food fortification is often optional, inconsistent, inadequate, or nonexistent [1]. In common with most population subgroups, except infants, adults aged 65 years old or over depend on sunlight for most of their VitD requirements [1, 2]. However, many variables influence the amount of ultraviolet (UV) B (290-315 mm) radiation that reaches the skin and its effectiveness. These include time of day, latitude, altitude, clothing, sunscreen use, pigmentation and age itself $[3,4]$. Indeed, even regularly exposed to sunlight, older adults produce $75 \%$ less cutaneous VitD than younger adults making them more prone to develop VitD deficiency, defined as a serum or plasma 25hydroxyvitamin $\mathrm{D}(25(\mathrm{OH}) \mathrm{D})$ concentration lower than $10 \mathrm{ng} / \mathrm{mL}$ (i.e., $25 \mathrm{nmol} / \mathrm{L}$ ) [4]. In our northern latitudes (including Switzerland), between November and March, there are insufficient UV-B rays to produce VitD. Some reports asserted that $15 \%$ of healthier community-dwelling old adults remain VitD insufficient even during summertime, while only $30 \%$ reached the desirable plasma levels ( $>30 \mathrm{ng} / \mathrm{mL}$ or $75 \mathrm{nmol} / \mathrm{L}$ ) at the end of the summer season [5]. Moreover, recent studies have shown that, in the last 10 years alone, serum VitD levels fell on average by $20 \%$ [6]. Even though recent evidence suggested that inter-laboratory variability may also contribute to the interpretation of this estimate $[7,8]$, VitD deficiency is increasingly being recognized as a worldwide epidemic $[2,9,10]$. This statement has led to consider that most of the world's adult population will not be getting an amount of VitD sufficient to maintain healthy bone mass and minimize risk of fracture and of falls $[2,11]$. In addition to these usual impacts on bone health, calcium and phosphorus metabolism, decreased VitD status, and/or dietary intakes of VitD have been demonstrated to decrease muscle strength and to increase the risk of type 2 diabetes, atherosclerosis, and neoplastic and immune disorders such as type 1 diabetes mellitus and multiple sclerosis $[1,2,12]$. These findings have led to suggest that VitD could play a role in regulating specific facets of human 
immunity $[12,13]$. This was reinforced by the fact that the $\mathrm{VitD}$ receptor (VDR), the receptor that mediates all known vitamin-related biological effects, is widely expressed on cells of the immune system (see Figure 1) [14-16]. This paper will aim to examine how VitD may contribute to limiting the burden of influenza infection in the aged adults, a population in which this burden remains considerable. Furthermore, considerations will be given on how VitD status may play a role in host resistance to influenza virus as well as influence the vaccine immunogenicity and this by its effects on both arms of the immune system (i.e., innate and adaptive immunity).

\section{Why Does Seasonal Influenza Infection Remain a Considerable Burden in the Elderly Population?}

Worldwide, seasonal influenza infection continues having a considerable impact. Annual estimates indicate that influenza virus causes 3-5 million severe cases resulting in 250,000 to 350,000 deaths worldwide $[18,19]$. The highest influenza infection prevalence occurs amongst older adults especially those with chronic medical conditions or immunological disorders. These are causal factors for the increased mortality observed within these high-risk groups [20]. However, mortality is just the tip of the iceberg in terms of disease burden. Recent data demonstrated that influenza can act as a trigger for functional decline leading to disability in some aged individuals and also contributes to excessive hospitalizations, medical visits, and antibiotic prescriptions $[21,22]$. Such outcomes represent an additional considerable economic burden amounting to $\$ 87$ billion each year in the United States [23]. This burden is partly explained by the age-related decline both in nonspecific and specific immune responses leading, respectively, to a weaker host capacity to resist influenza virus and to a less optimal immune response to immunization.

\subsection{The Nonimmune Specific Mechanisms That Facilitate} Influenza Infection. The respiratory tract represents the primary site for the introduction and deposition of potentially pathogenic microorganisms into the body including influenza virus, and this is mainly through inspired air. Defences of the respiratory tract involve both mechanical factors, mucociliary escalator, receptor, and effector molecules of the innate immune system [24]. One of the key players of the defence system is the ciliated epithelium lining the airway which acts through the physical removal both by the ciliary clearance and the cough reflex. In addition, the presence of broad-spectrum antimicrobial agents in the mucus acting as surfactant, the presence of phospholipase A2, the recruitment of phagocytic cells and an inflammatory response all work in collaboration to defend the airways [25]. Although, this sophisticated defence system is weakened with advancing age and even in the absence of overt lung disease [26-31], the intrathoracic dwell time of influenza viruses is increased [29,32] facilitating any transepithelial migration of the viral particles. Advancing age is, therefore, negatively associated with nasal, large and small airways ciliary clearance. This is due to significantly slower ciliary beat frequency and longer mucociliary clearance time $[26,27]$. In addition, mechanical defences are modified by the loss of lung elastic recoil together with increased compliance of the intraparenchymal airway [28]. As demonstrated by experiments on aerosol transmission of influenza virus the tidal breathing volume declines in the aged individuals [31]. Those people often show impaired ventilation function (measured by the FEV1 expressed as a percentage of the volume predicted) which may be due in part to decreased respiratory muscle strength leading to a less forceful coughing [29]. Complementarily, the sensitivity of cough reflex is also decreased throughout all the nasosinusal and tracheobronchial tree [30]. Even if there is no evidence of changes in the cells producing surfactant and modifications of its composition, aged individuals have been found to be subject to a chronic low-grade inflammation which resembles to the one observed in COPD patients. However, similarities are restricted only to qualitative aspects and not quantitative [33]. As the primary contact of pathogens with the adaptive immune system is via the antigen-presenting cells (APCs), the age-related decline in the numbers of these cells contributes to severely impact strategies for coping with influenza. Further impact on the defense against influenza may follow because of alterations in the response to tolllike receptor (TLR) ligands. In a recent study, Panda et al. found substantial decreases in older compared with young individuals concerning TNF- $\alpha$, IL-6, and/or IL-12 (p40) production in myeloid dendritic cells in response to TLR $1 / 2$, TLR2/6, TLR3, TLR5, and TLR8 engagement, as well as tumor necrosis factor (TNF) $\alpha$ and interferon (IFN) $\alpha$ production in plasmacytoid dendritic cells in response to TLR7 and TLR9 engagement [34]. Authors also found higher intracellular cytokine production in the absence of TLR ligand stimulation by APCs in older compared with younger counterparts, suggesting some dysfunction in the regulation of cytokine production. Moreover, they showed a strong association between poor antibody responses to influenza immunization and impaired TLR function in the older individuals. In addition, fever, which is one of the cardinal signs of influenza infection [35], may be absent or blunted $20 \%-$ $30 \%$ of the time in the aged population [36], thus, leading to facilitated virus spreading.

\subsection{Influenza Vaccine: A Vaccine Less Effective in the Elderly} Than Previously Believed. The current trivalent inactivated influenza vaccines (TIVs) contain $15 \mu \mathrm{g}$ of hemagglutinin (HA) of each of the three strains $(\mathrm{A} / \mathrm{H} 1 \mathrm{~N} 1, \mathrm{~A} / \mathrm{H} 3 \mathrm{~N} 2$, and influenza $\mathrm{B}$ ), stimulating a response in both $\mathrm{B}$ and Tcells, resulting in humoral and cell-mediated immunity, respectively $[17,37]$. As depicted by Figure 2, vaccine antigens are taken up by APCs, such as macrophages and dendritic cells (DCs). The local innate immune response facilitates maturation of DCs, which present stable major histocompatibility complex/peptide complexes. Mature DCs migrate into regional lymph nodes, where they induce activation and clonal expansion of naive CD4+ T-helper and CD8+ 

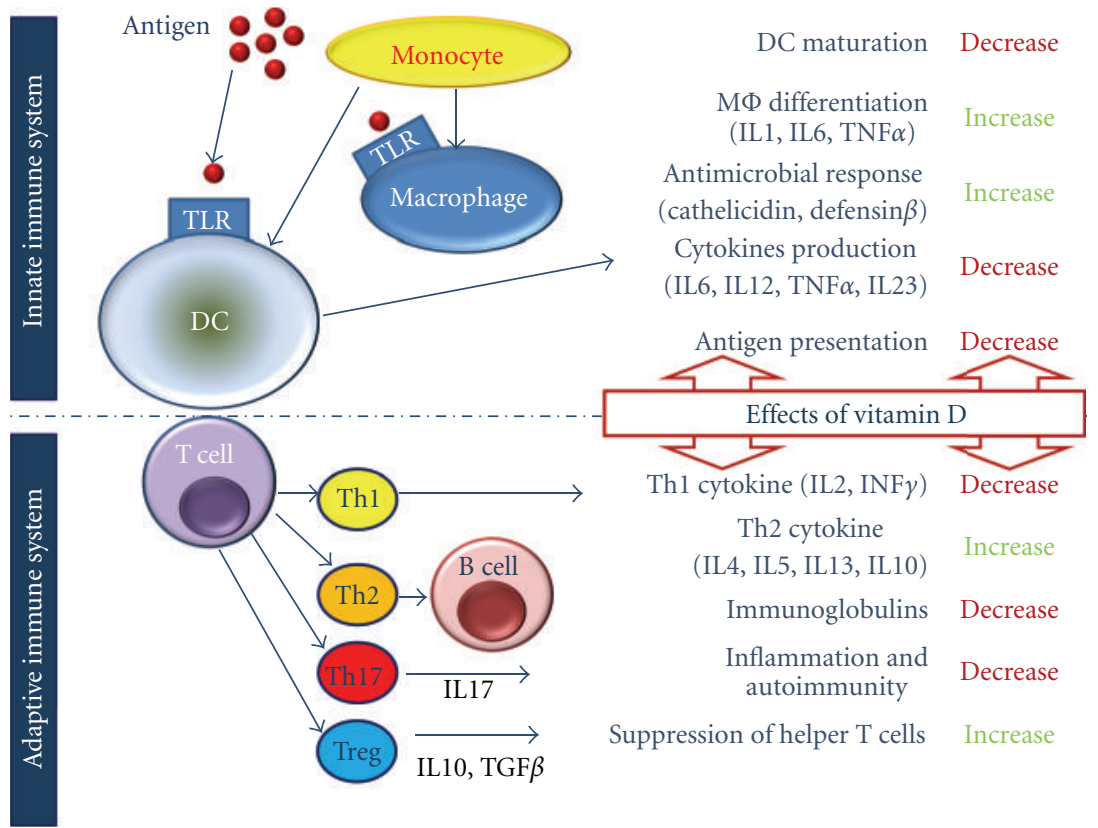

FIGURE 1: Schematic representation of the immune effects of vitamin D: this figure depicts the principal innate and adaptive immune responses to an antigenic challenge and the influence of vitamin D (positive regulation: increase or negative regulation: decrease) on these responses (B cell: B lymphocyte, cyto T cell, cytotoxic T cell, DC: dendritic cell, MФ: macrophage T cell: T lymphocyte; TLR: toll-like receptor; TH: helper T cell; Treg: regulatory T cell; IL: interleukin; TNF: tumor necrosis factor; and INF: interferon).

cytotoxic T cells. The activation and differentiation of naive $\mathrm{B}$ cells is induced by antigen and CD4+ T-helper cells. Naive B cells differentiate into memory B cells and antibodysecreting B cells. Long-term immunity is assured by memory $\mathrm{B}$ and $\mathrm{T}$ cells in the blood and lymph nodes, as well as by long-lived plasma cells and memory $\mathrm{T}$ cells in the bone marrow. TIVs are considered as both effective and cost saving in preventing influenza infection in the aged population $[18,19]$. However, in spite of widespread application of immunization programmes, rates of hospitalization for acute respiratory illness and cardiovascular disease have been increased in population aged over 65 years during the annual influenza seasons $[18,19]$. Thus, vaccine effectiveness, defined as the reduction in attack rates between vaccinated and unvaccinated population, expected to be between 70 and $90 \%$ in younger adults is considerably reduced to less than $40 \%$ over the age of 65 years [19]. This inability of the immune system to amount an effective response results from a multitude of changes occurring in the immune system when we age. These changes are evident both in the innate immunity and in the adaptive immune system $[38,39]$. The cumulative of a life-long reshaping and adaptation of the immune system, in response to exposure to a plethora of pathogenic challenges [40], cellular and molecular changes [41-43], as well as thymic involution [44], is believed to result in this dysfunctional immunity. However, failure of the immune system to provide protection to the body faced with influenza antigen is not only related to immunosenescence [38], but factors such as chronic comorbid conditions [45, 46], nutritional status [47, 48], and hormonal pathway dysregulation $[49,50]$ seem to be important contributory factors as well [46].

\section{Is VitD a Potential Immune-Enhancing Agent against Influenza?}

In order to enhance the immune response and make the ageing body more prone to protect itself from influenza virus, novel vaccine designs and immunological therapeutic approaches have been developed [19]. Whether modestly increased immunogenicity was measured when administrating new adjuvanted, intradermal, or high-dose vaccines, slightly higher side effects have led to lower acceptability [51]. Strategies reaching the goal of rejuvenating the immune system and usually mentioned as the 3R's of rejuvenation (restoration, replacement, and reprogramming) [43] have been mainly achieved in experimental systems. However, no clinical translation of these results is currently available [52], except strategies using nutrients and protein-energy supplements that included VitD as well $[12,53,54]$.

\subsection{Does VitD Have an Anti-Infectious Effect?}

Recently, there has been a great deal of interest in the role played by VitD in host resistance to infection, and a number of scientific claims reported broad anti-infectious effects, potentially beneficial in people infected with influenza [13, $55,56]$. This emerging role of $\mathrm{VitD}$ in innate immunity results in two findings: the immune system is able to produce 


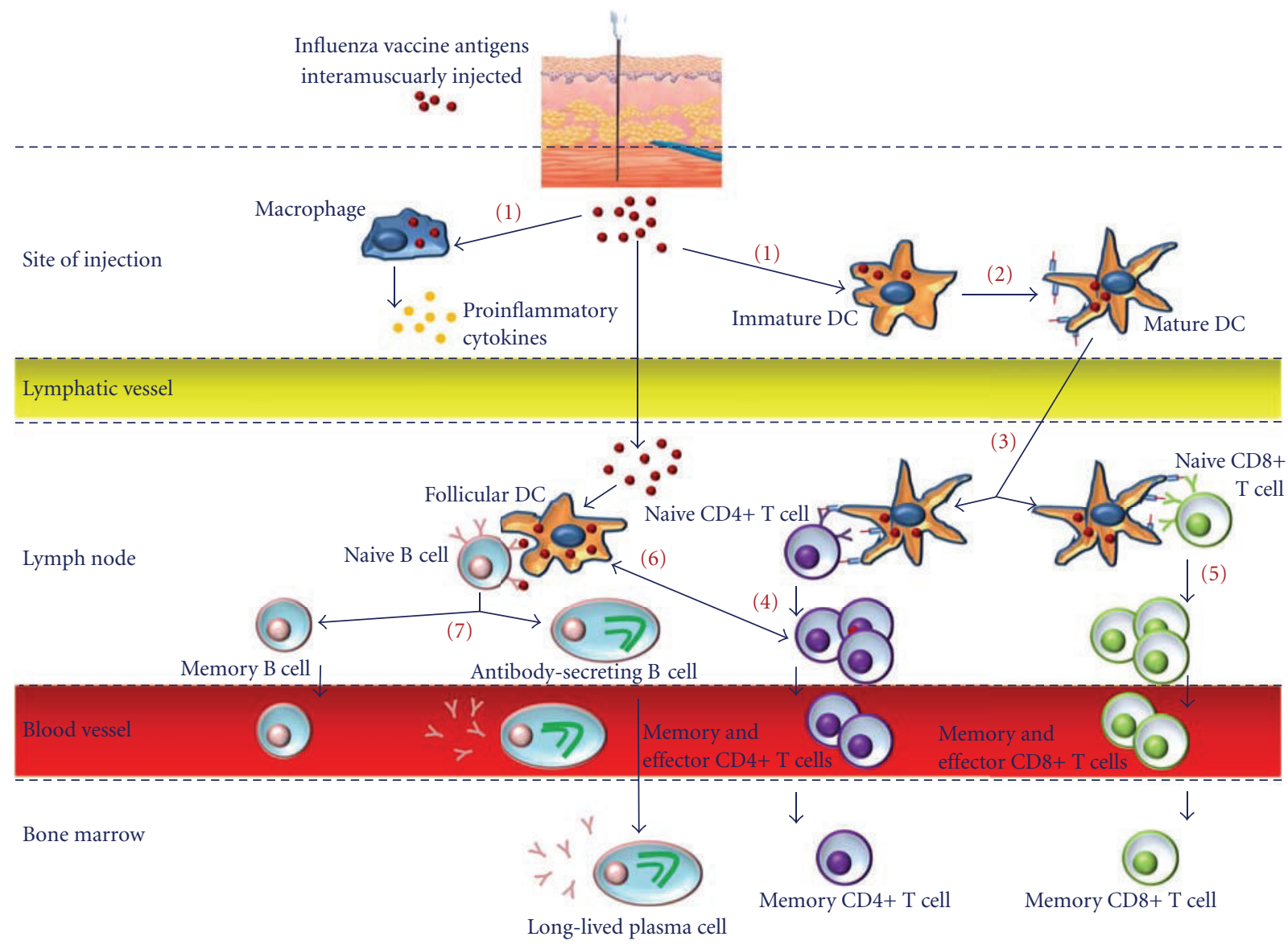

FIGURE 2: The normal immune response following influenza vaccination. Administration of vaccine antigens induces the activation of the innate immune responses at the site of injection. The antigen is taken up by antigen-presenting cells (1), such as macrophages and dendritic cells (DCs). The local innate immune response facilitates maturation of DCs, which present stable major histocompatibility complex/peptide complexes (2). Mature DCs migrate into lymph nodes (3), where they induce activation and clonal expansion of naive CD4+ (4) and CD8+ (5) T cells. The activation and differentiation of naive B cells is induced by antigen and CD4+ T helper cells (6). Naive B cells differentiate into memory B cells and antibody-secreting B cells (7). Long-term immunity is assured by memory B and T cells in the blood and lymph nodes, as well as by long-lived plasma cells and memory $\mathrm{T}$ cells in the bone marrow (adapted from [17]).

$1 \alpha$-hydroxylase, the enzyme that converts circulating VitD to its active form [57-60] and the active VitD produced in the immune system led to the production and regulation of antimicrobial peptides such as cathelicidin and defensin $\beta 2$ $[13,61]$ which in turn inhibited replication of Mycobacterium tuberculosis, in vitro [62]. However, recent randomized controlled trials using VitD supplementation (3 doses of 100.000 UI) showed no beneficial effect in clinical outcomes or mortality in tuberculosis [63] while a meta-analysis demonstrated a positive association between VDR polymorphisms with risk of tuberculosis [64]. Even though the latter supported the hypothesis that VitD deficiency might play a role as a risk factor during the development of tuberculosis, another report in dialysis patients showed no association between VitD supplementation and decreased risk of the infection [65]. Evidence that VitD affects clearance of selected infections is also supported by epidemiological data showing an inverted association between serum $25(\mathrm{OH}) \mathrm{D}$ level and upper respiratory tract infection incidence rates $[6,66]$. This effect was attributed to VitD regulation of antimicrobial peptides such as cathelicidin [61]. In humans, the only known cathelicidin is hCAP-18. It enhances microbial killing in phagocytic vacuoles, acts as chemoattractant for neutrophils and monocytes, and has a defined VitDdependent mechanism [67, 68]. As depicted by Figure 1, pathogenic antigens interact with TLRs on macrophages to upregulate the expression of genes that code for the VDR and the $1 \alpha$-hydroxylase enzyme $[62,69,70]$. In turn, the biologically active $1,25(\mathrm{OH})_{2} \mathrm{D}$ enhances cathelicidin synthesis by interacting with the promoter of the hCAP-18 [71-73]. However, in order to activate hCAP-18 and enhance macrophage function, it is necessary to reach sufficient levels of the circulating form of VitD $[6,62,73]$. Thus, serum 25(OH)D level of $30 \mathrm{ng} / \mathrm{mL}$ (i.e., $75 \mathrm{nmol} / \mathrm{L}$ ) or more is necessary for the optimal induction of cathelicidin messenger RNA. Interestingly, higher levels $(40 \mathrm{ng} / \mathrm{mL}$ or $100 \mathrm{nmol} / \mathrm{L})$ do not provide additional benefit [6]. Thus, some hypothesized that wintertime VitD insufficiency may explain seasonal variation in influenza infection [61]. Whilst many reports demonstrated the effect of vitamin $\mathrm{D}$ on the increased 
expression of antimicrobial peptides [13,61, 74], the effect of either VitD or $1,25(\mathrm{OH})_{2} \mathrm{D}$ on these specific peptides against influenza infection has not been tested in vitro nor in vivo [13]. All together these findings demonstrate that it is still difficult to predict what the exact effect of VitD would be on host resistance to influenza virus.

\subsection{How Could Vitamin D Modulate Influenza Vaccine Immunogenicity?}

Recent studies have demonstrated potent effects of VitD on cytokine production and in regulating normal innate and adaptive immune functions in animals and humans [1316]. Indeed, as shown in Figure 1, the immunomodulatory effects of VitD are thought to be mediated via (i) its action on APCs with the most potent reported effects on DCs [75-77], (ii) T-cell proliferation and cytokine production with inhibition of the Th1-like cytokines (interleukin (IL)2, IFN $\gamma$ ), increase of the Th2-like cytokines (IL4, IL5, IL10 and IL13) and of the Th17-like cytokine (IL17) [78, 79], and (iii) through direct effects on B-cell homeostasis, proliferation, and immunoglobulin production $[80,81]$. Potential effects on a fourth group of CD4+ $\mathrm{T}$ cells exerting suppressor rather than effector functions and known as regulatory $\mathrm{T}$ cells or Tregs have been also suspected [82-85]. As a result, VitD coadministrated with TIV in mice was shown to enhance the anti-HA antibody response and mucosal immunity [86]. In humans, no significant difference in HA inhibition titers was detected in a randomized controlled study conducted in healthy volunteers ranging in age from 18 to 49 years, vaccinated with TIV, and randomized for $1,25(\mathrm{OH})_{2} \mathrm{D}$ or placebo [54]. Three important limitations to the conclusion are, however, drawn from this study. First, the subjects in this study were young and healthy, and, because their serum $25(\mathrm{OH}) \mathrm{D}$ level at baseline was not measured, we can easily consider that these individuals were not VitD deficient. Second, significant prevaccination HA titers were measured in nearly all subjects. This indicates that the subject had considerable immunity to the three vaccine influenza strains before their vaccination. Since a clear inverse relationship exists between preimmunization serum HA antibody levels and antibody increase after vaccination, this could have masked the potential immunomodulatory effect of VitD [19]. Third, vitamin supplementation and vaccine were simultaneously injected. Even if the study used the active form of VitD, the delay between the two injections was too limited to expect any beneficial biological effects on $\mathrm{B}$ and $\mathrm{T}$ cells or on components of innate immunity. More recently, Chadha et al. investigated the influence of baseline serum $25(\mathrm{OH}) \mathrm{D}$ level on serological response to TIV vaccination [53]. While the results demonstrated that there was a significant effect of baseline $25(\mathrm{OH}) \mathrm{D}$ when tested as a continuous variable in relation to serological response, the study conclusions were also affected by three important limitations. First, subjects enrolled in the study were only men with cancer, a comorbid condition well known by itself as limiting immune system capacities. Second, at baseline a large number of patients were taking high dose of VitD with a median dose of $2000 \mathrm{IU} /$ day (dose range from 800 to $9.000 \mathrm{UI})$. Enrolled subjects had median 25(OH)D level of $44.88 \mathrm{ng} / \mathrm{mL}$ (i.e., $112.2 \mathrm{nmol} / \mathrm{L}$ ), much higher than values usually found in most cancer patients population (i.e., 22$23 \mathrm{ng} / \mathrm{mL}$ or $55-58 \mathrm{nmol} / \mathrm{L}$ ) [87]. Third, the small sample size of 60 subjects has probably underpowered the study design. While the beneficial effect observed only with the $\mathrm{A} / \mathrm{H} 3 \mathrm{~N} 2$ strain correlated with previous findings from a randomized controlled trial of $\mathrm{Vit} D$ supplementation versus placebo in school children [88]; responses to individual strains of influenza vaccine among patients with lowest and highest quartile of $25(\mathrm{OH}) \mathrm{D}$ level were not different for A/H1N1 and B strains. Also, when any virus strains were considered, the difference between the vaccine response rates were insignificant, despite a $30 \%$ difference between the two groups.

Finally, similar to potential antimicrobial effects of VitD, more evidence is still needed in humans in order to determine if there is a true causal link between changes in VitD and immune system regulation. Continued evaluation of the consequences of Vit D insufficiency appears warranted. Future studies should address the question whether VitD supplementation enhances immune response to influenza vaccination in nonsupplemented population with low baseline serum $25(\mathrm{OH})$ levels and thus preventing influenza clinical outcomes.

\section{Conclusion}

Influenza infection remains a major public health concern across the world. The overall body of evidence suggests that older adults are more prone to be infected by influenza virus. While influenza prevention strategies are mainly based on immunization, current influenza vaccines do not offer optimal protection in this population due, in part, to waning immunity. Even if VitD has profound effects on immunity and clinical and epidemiological data suggest that VitD insufficiency increases susceptibility to influenza infection, there is not yet sufficient information to clarify the true relationship between VitD status and host resistance or influenza vaccine immunogenicity. It is, therefore, premature at this time to recommend "booster" VitD supplementations at the beginning of annual influenza seasons in order to prevent infection in the elderly population. However, assessing VitD status and maintaining optimal serum levels should be considered in all ageing and old adults in order to prevent bone and promote healthy ageing.

\section{Conflict of Interests}

No sources of funding were used to assist in the preparation of the paper. The authors have no conflict of interest that are directly relevant to the content of this paper.

\section{References}

[1] M. F. Holick, "Sunlight and vitamin D for bone health and prevention of autoimmune diseases, cancers, and cardiovascular disease," The American Journal of Clinical Nutrition, vol. 80, no. 6, supplement, pp. 1678S-1688S, 2004. 
[2] C. J. Rosen, "Clinical practice. Vitamin D insufficiency," The New England Journal of Medicine, vol. 364, no. 3, pp. 248-254, 2011.

[3] K. D. Cashman, J. M. W. Wallace, G. Horigan et al., "Estimation of the dietary requirement for vitamin $\mathrm{D}$ in free-living adults $\geq 64$ y of age," American Journal of Clinical Nutrition, vol. 89, no. 5, pp. 1366-1374, 2009.

[4] K. A. Kennel, M. T. Drake, and D. L. Hurley, "Vitamin D deficiency in adults: when to test and how to treat," Mayo Clinic Proceedings, vol. 85, no. 8, pp. 752-758, 2010.

[5] R. Theiler, H. B. Stähelin, A. Tyndall, K. Binder, G. Somorjai, and H. A. Bischoff, "Calcidiol, calcitriol and parathyroid hormone serum concentrations in institutionalized and ambulatory elderly in Switzerland," International Journal for Vitamin and Nutrition Research, vol. 69, no. 2, pp. 96-105, 1999.

[6] A. A. Ginde, J. M. Mansbach, and C. A. Camargo, "Association between serum 25-hydroxyvitamin D level and upper respiratory tract infection in the third national health and nutrition examination survey," Archives of Internal Medicine, vol. 169, no. 4, pp. 384-390, 2009.

[7] B. Hamilton, "Vitamin D and human skeletal muscle," Scandinavian Journal of Medicine and Science in Sports, vol. 20, no. 2, pp. 182-190, 2010.

[8] N. Binkley, D. Krueger, C. S. Cowgill et al., "Assay variation confounds the diagnosis of hypovitaminosis D: a call for standardization," Journal of Clinical Endocrinology and Metabolism, vol. 89, no. 7, pp. 3152-3157, 2004.

[9] N. Binkley, R. Novotny, D. Krueger et al., "Low vitamin D status despite abundant sun exposure," Journal of Clinical Endocrinology and Metabolism, vol. 92, no. 6, pp. 2130-2135, 2007.

[10] M. T. Hannan, H. J. Litman, A. B. Araujo et al., "Serum 25-hydroxyvitamin D and bone mineral density in a racially and ethnically diverse group of men," Journal of Clinical Endocrinology and Metabolism, vol. 93, no. 1, pp. 40-46, 2008.

[11] A. W. Norman, R. Bouillon, S. J. Whiting, R. Vieth, and P. Lips, "13th Workshop consensus for vitamin D nutritional guidelines," Journal of Steroid Biochemistry and Molecular Biology, vol. 103, no. 3-5, pp. 204-205, 2007.

[12] P. Sanderson, R. L. Elsom, V. Kirkpatrick et al., "UK food standards agency workshop report: diet and immune function," British Journal of Nutrition, vol. 103, no. 11, pp. 1684-1687, 2010.

[13] D. Bruce, J. H. Ooi, S. Yu, and M. T. Cantorna, "Vitamin D and host resistance to infection? Putting the cart in front of the horse," Experimental Biology and Medicine, vol. 235, no. 8, pp. 921-927, 2010.

[14] M. Hewison, "Vitamin D and the immune system: new perspectives on an old theme," Endocrinology and Metabolism Clinics of North America, vol. 39, no. 2, pp. 365-379, 2010.

[15] M. R. Haussler, G. K. Whitfield, C. A. Haussler et al., "The nuclear vitamin D receptor: biological and molecular regulatory properties revealed," Journal of Bone and Mineral Research, vol. 13, no. 3, pp. 325-349, 1998.

[16] C. Mathieu and L. Adorini, "The coming of age of 1,25-dihydroxyvitamin D3 analogs as immunomodulatory agents," Trends in Molecular Medicine, vol. 8, no. 4, pp. 174-179, 2002.

[17] P. O. Lang, S. Govind, J. P. Michel, R. Aspinall, and W. A. Mitchell, "Immunosenescence: implications for vaccination programmes in adults," Maturitas, vol. 68, no. 4, pp. 322-330, 2011.
[18] P. O. Lang, S. Govind, W. A. Mitchell et al., "Influenza vaccine effectiveness in aged individuals: the role played by cellmediated immunity," European Geriatric Medicine, vol. 1, no. 4, pp. 233-238, 2010.

[19] P. O. Lang, S. Govind, W. A. Mitchell, C. A. Siegrist, and R. Aspinall, "Vaccine effectiveness in older individuals: what has been learned from the influenza-vaccine experience," Ageing Research Reviews, vol. 10, pp. 389-395, 2011.

[20] World Health Organization, "Influenza vaccines," The Weekly Epidemiological Record, vol. 80, pp. 279-287, 2005.

[21] A. S. Monto, F. Ansaldi, R. Aspinall et al., "Influenza control in the 21st century: optimizing protection of older adults," Vaccine, vol. 27, no. 37, pp. 5043-5053, 2009.

[22] J. E. McElhaney and R. B. Effros, "Immunosenescence: what does it mean to health outcomes in older adults?" Current Opinion in Immunology, vol. 21, no. 4, pp. 418-424, 2009.

[23] N. A. M. Molinari, I. R. Ortega-Sanchez, M. L. Messonnier et al., "The annual impact of seasonal influenza in the US: measuring disease burden and costs," Vaccine, vol. 25, no. 27, pp. 5086-5096, 2007.

[24] J. M. Alonso, "Immunity and pathophysiology of respiratory tract infections," Medecine et Maladies Infectieuses, vol. 38, no. 8, pp. 433-437, 2008.

[25] G. Diamond, D. Legarda, and L. K. Ryan, "The innate immune response of the respiratory epithelium," Immunological Reviews, vol. 173, pp. 27-38, 2000.

[26] J. C. Ho, K. N. Chan, W. H. Hu et al., "The effect of aging on nasal mucociliary clearance, beat frequency, and ultrastructure of respiratory cilia," American Journal of Respiratory and Critical Care Medicine, vol. 163, no. 4, pp. 983-988, 2001.

[27] M. Svartengren, R. Falk, and K. Philipson, "Long-term clearance from small airways decreases with age," European Respiratory Journal, vol. 26, no. 4, pp. 609-615, 2005.

[28] R. J. Knudson, D. F. Clark, T. C. Kennedy, and D. E. Knudson, "Effect of aging alone on mechanical properties of the normal adult human lung," Journal of Applied Physiology Respiratory Environmental and Exercise Physiology, vol. 43, no. 6, pp. 10541062, 1977.

[29] A. S. Buchman, P. A. Boyle, R. S. Wilson, L. Gu, J. L. Bienias, and D. A. Bennett, "Pulmonary function, muscle strength and mortality in old age," Mechanisms of Ageing and Development, vol. 129, no. 11, pp. 625-631, 2008.

[30] D. M. Newnham and S. J. C. Hamilton, "Sensitivity of the cough reflex in young and elderly subjects," Age and Ageing, vol. 26, no. 3, pp. 185-188, 1997.

[31] R. H. Alford, J. A. Kasel, P. J. Gerone, and V. Knight, "Human influenza resulting from aerosol inhalation," Proceedings of the Society for Experimental Biology and Medicine, vol. 122, no. 3, pp. 800-804, 1966.

[32] H. J. Schunemann, J. Dorn, B. J. B. Grant, W. Winkelstein, and M. Trevisan, "Pulmonary function is a long-term predictor of mortality in the general population: 29-Year follow-up of the Buffalo Health Study," Chest, vol. 118, no. 3, pp. 656-664, 2000.

[33] K. C. Meyer, N. S. Rosenthal, P. Soergel, and K. Peterson, "Neutrophils and low-grade inflammation in the seemingly normal aging human lung," Mechanisms of Ageing and Development, vol. 104, no. 2, pp. 169-181, 1998.

[34] A. Panda, F. Qian, S. Mohanty et al., "Age-associated decrease in TLR function in primary human dendritic cells predicts influenza vaccine response," Journal of Immunology, vol. 184, no. 5, pp. 2518-2527, 2010.

[35] T. R. Traynor, J. A. Majde, S. G. Bohnet, and J. M. Krueger, "Interferon type I receptor-deficient mice have altered disease 
symptoms in response to influenza virus," Brain, Behavior, and Immunity, vol. 21, no. 3, pp. 311-322, 2007.

[36] D. C. Norman, "Fever in the elderly," Clinical Infectious Diseases, vol. 31, no. 1, pp. 148-151, 2000.

[37] B. Weinberger, D. Herndler-Brandstetter, A. Schwanninger, D. Weiskopf, and B. Grubeck-Loebenstein, "Biology of immune responses to vaccines in elderly persons," Clinical Infectious Diseases, vol. 46, no. 7, pp. 1078-1084, 2008.

[38] P. O. Lang, W. A. Mitchell, A. Lapenna, D. Pitts, and R. Aspinall, "Immunological pathogenesis of main age-related diseases and frailty: role of immunosenescence," European Geriatric Medicine, vol. 1, no. 2, pp. 112-121, 2010.

[39] D. Weiskopf, B. Weinberger, and B. Grubeck-Loebenstein, "The aging of the immune system," Transplant International, vol. 22, no. 11, pp. 1041-1050, 2009.

[40] H. W. Virgin, E. J. Wherry, and R. Ahmed, "Redefining chronic viral infection," Cell, vol. 138, no. 1, pp. 30-50, 2009.

[41] T. Fulop, A. Larbi, N. Douziech et al., "Signal transduction and functional changes in neutrophils with aging," Aging Cell, vol. 3, no. 4, pp. 217-226, 2004.

[42] T. Fulop, A. Larbi, A. Wikby, E. Mocchegiani, K. Hirokawa, and G. Pawelec, "Dysregulation of T-cell function in the elderly: scientific basis and clinical implications," Drugs and Aging, vol. 22, no. 7, pp. 589-603, 2005.

[43] S. Govind, A. Lapenna, P. O. Lang, and R. Aspinall, "Immunotherapy of immunosenescence: who, how and when," Open Longevity Science. In press.

[44] R. Aspinall, D. Pitts, A. Lapenna, and W. Mitchell, "Immunity in the elderly: the role of the thymus," Journal of Comparative Pathology, vol. 142, no. 1, pp. S111-S115, 2010.

[45] T. Fulop, A. Larbi, J. M. Witkowski et al., "Aging, frailty and age-related diseases," Biogerontology, vol. 11, no. 5, pp. 547$563,2010$.

[46] T. Fulop, G. Pawelec, S. Castle, and M. Loeb, "Immunosenescence and vaccination in nursing home residents," Clinical Infectious Diseases, vol. 48, no. 4, pp. 443-448, 2009.

[47] B. Lesourd, "Nutritional factors and immunological ageing," Proceedings of the Nutrition Society, vol. 65, no. 3, pp. 319-325, 2006.

[48] W. Savino and M. Dardenne, "Nutritional imbalances and infections affect the thymus: consequences on T-cell-mediated immune responses," Proceedings of the Nutrition Society, vol. 69, pp. 636-643, 2010.

[49] J. C. O’Connor, R. H. McCusker, K. Strle, R. W. Johnson, R. Dantzer, and K. W. Kelley, "Regulation of IGF-I function by proinflammatory cytokines: at the interface of immunology and endocrinology," Cellular Immunology, vol. 252, no. 1-2, pp. 91-110, 2008.

[50] K. W. Kelley, D. A. Weigent, and R. Kooijman, "Protein hormones and immunity," Brain, Behavior, and Immunity, vol. 21, no. 4, pp. 384-392, 2007.

[51] V. Parodi, D. De Florentiis, M. Martini, and F. Ansaldi, "Inactivated influenza vaccines: recent progress and implications for the elderly," Drugs and Aging, vol. 28, no. 2, pp. 93-106, 2011.

[52] P. O. Lang and R. Aspinall, "Immunosenescence and herd immunity: with an ever increasing aging population do we need to rethink vaccine schedules?" Expert Review of Vaccines. In press.

[53] M. K. Chadha, M. Fakih, J. Muindi et al., "Effect of 25-hydroxyvitamin D status on serological response to influenza vaccine in prostate cancer patients," Prostate, vol. 71, no. 4, pp. 368-372, 2011.

[54] J. D. Kriesel and J. Spruance, "Calcitriol (1,25-dihydroxyvitamin D3) coadministered with influenza vaccine does not enhance humoral immunity in human volunteers," Vaccine, vol. 17, no. 15-16, pp. 1883-1888, 1999.

[55] R. F. Edlich, S. S. Mason, J. J. Dahlstrom, E. Swainston, W. B. Long Iii, and K. D. Gubler, "Pandemic preparedness for swine flu influenza in the united states," Journal of Environmental Pathology, Toxicology and Oncology, vol. 28, no. 4, pp. 261-264, 2009.

[56] M. R. Goldstein, L. Mascitelli, and F. Pezzetta, "Pandemic influenza A (H1N1): mandatory vitamin D supplementation?" Medical Hypotheses, vol. 74, no. 4, p. 756, 2010.

[57] M. T. Abreu, Y. Kantorovich, E. A. Vasiliauskas et al., "Measurement of vitamin D levels in inflammatory bowel disease patients reveals a subset of Crohn's disease patients with elevated 1,25-dihydroxyvitamin D and low bone mineral density," Gut, vol. 53, no. 8, pp. 1129-1136, 2004.

[58] M. Hewison, F. Burke, K. N. Evans et al., "Extra-renal 25hydroxyvitamin D3-1 $\alpha$-hydroxylase in human health and disease," Journal of Steroid Biochemistry and Molecular Biology, vol. 103, no. 3-5, pp. 316-321, 2007.

[59] N. Liu, L. Nguyen, R. F. Chun et al., "Altered endocrine and autocrine metabolism of vitamin D in a mouse model of gastrointestinal inflammation," Endocrinology, vol. 149, no. 10, pp. 4799-4808, 2008.

[60] E. Kállay, G. Bises, E. Bajna et al., "Colon-specific regulation of vitamin D hydroxylases-A possible approach for tumor prevention," Carcinogenesis, vol. 26, no. 9, pp. 1581-1589, 2005.

[61] J. J. Cannell, R. Vieth, J. C. Umhau et al., "Epidemic influenza and vitamin D," Epidemiology and Infection, vol. 134, no. 6, pp. 1129-1140, 2006.

[62] P. T. Liu, S. Stenger, H. Li et al., "Toll-like receptor triggering of a vitamin D-mediated human antimicrobial response," Science, vol. 311, no. 5768, pp. 1770-1773, 2006.

[63] C. Wejse, V. F. Gomes, P. Rabna et al., "Vitamin D as supplementary treatment for tuberculosis: a double-blind, randomized, placebo-controlled trial," American Journal of Respiratory and Critical Care Medicine, vol. 179, no. 9, pp. 843-850, 2009.

[64] L. Gao, Y. Tao, L. Zhang, and Q. Jin, "Vitamin D receptor genetic polymorphisms and tuberculosis: updated systematic review and meta-analysis," International Journal of Tuberculosis and Lung Disease, vol. 14, no. 1, pp. 15-23, 2010.

[65] A. I. Christopoulos, A. A. Diamantopoulos, P. A. Dimopoulos, D. S. Goumenos, and G. A. Barbalias, "Risk factors for tuberculosis in dialysis patients: a prospective multi-center clinical trial," BMC Nephrology, vol. 10, no. 1, article 36, 2009.

[66] J. S. Adams and M. Hewison, "Unexpected actions of vitamin D: new perspectives on the regulation of innate and adaptive immunity," Nature Clinical Practice Endocrinology and Metabolism, vol. 4, no. 2, pp. 80-90, 2008.

[67] A. F. Gombart, N. Borregaard, and H. P. Koeffler, "Human cathelicidin antimicrobial peptide (CAMP) gene is a direct target of the vitamin D receptor and is strongly up-regulated in myeloid cells by 1,25-dihydroxyvitamin D3," FASEB Journal, vol. 19, no. 9, pp. 1067-1077, 2005.

[68] P. T. Liu, S. Stenger, D. H. Tang, and R. L. Modlin, "Cutting edge: vitamin D-mediated human antimicrobial activity against Mycobacterium tuberculosis is dependent on the induction of cathelicidin," Journal of Immunology, vol. 179, no. 4, pp. 2060-2063, 2007.

[69] H. Reichel, H. P. Koeffler, J. E. Bishop, and A. W. Norman, "25-Hydroxyvitamin D3 metabolism by lipopolysaccharidestimulated normal human macrophages," Journal of Clinical Endocrinology and Metabolism, vol. 64, no. 1, pp. 1-9, 1987. 
[70] E. Y. Enioutina, D. Bareyan, and R. A. Daynes, "TLR-induced local metabolism of vitamin D3 plays an important role in the diversification of adaptive immune responses," Journal of Immunology, vol. 182, no. 7, pp. 4296-4305, 2009.

[71] T. T. Wang, F. P. Nestel, V. Bourdeau et al., "Cutting edge: 1,25-Dihydroxyvitamin D3 is a direct inducer of antimicrobial peptide gene expression," Journal of Immunology, vol. 173, no. 5, pp. 2909-2912, 2004.

[72] S. Yim, P. Dhawan, C. Ragunath, S. Christakos, and G. Diamond, "Induction of cathelicidin in normal and CF bronchial epithelial cells by 1,25-dihydroxyvitamin D3," Journal of Cystic Fibrosis, vol. 6, no. 6, pp. 403-410, 2007.

[73] G. Weber, J. D. Heilborn, C. I. C. Jimenez, A. Hammarsjö, H. Törmä, and M. Ståhle, "Vitamin D induces the antimicrobial protein hCAP18 in human skin," Journal of Investigative Dermatology, vol. 124, no. 5, pp. 1080-1082, 2005.

[74] E. Leikina, H. Delanoe-Ayari, K. Melikov et al., "Carbohydrate-binding molecules inhibit viral fusion and entry by crosslinking membrane glycoproteins," Nature Immunology, vol. 6, no. 10, pp. 995-1001, 2005.

[75] G. Penna and L. Adorini, " $1 \alpha, 25$-dihydroxyvitamin D3 inhibits differentiation, maturation, activation, and survival of dendritic cells leading to impaired alloreactive $\mathrm{T}$ cell activation," Journal of Immunology, vol. 164, no. 5, pp. 24052411, 2000.

[76] A. G. S. Van Halteren, E. Van Etten, E. C. De Jong, R. Bouillon, B. O. Roep, and C. Mathieu, "Redirection of human autoreactive T-cells upon interaction with dendritic cells modulated by TX527, an analog of 1,25 dihydroxyvitamin D3," Diabetes, vol. 51, no. 7, pp. 2119-2125, 2002.

[77] D. D’Ambrosio, M. Cippitelli, M. G. Cocciolo et al., "Inhibition of IL-12 production by 1,25-dihydroxyvitamin D3. Involvement of NF- $\kappa \mathrm{B}$ downregulation in transcriptional repression of the p40 gene," Journal of Clinical Investigation, vol. 101, no. 1, pp. 252-262, 1998.

[78] A. Boonstra, F. J. Barrat, C. Crain, V. L. Heath, H. F. J. Savelkoul, and A. O'Garra, " $1 \alpha, 25$-Dihydroxyvitamin D3 has a direct effect on naive CD4+ T cells to enhance the development of Th2 cells," Journal of Immunology, vol. 167, no. 9, pp. 49744980, 2001.

[79] M. Cippitelli, C. Fionda, D. Di Bona et al., "Negative regulation of CD95 ligand gene expression by vitamin D3 in T lymphocytes," Journal of Immunology, vol. 168, no. 3, pp. 1154-1166, 2002.

[80] S. Chen, G. P. Sims, X. C. Xiao, Y. G. Yue, S. Chen, and P. E. Lipsky, "Modulatory effects of 1,25-dihydroxyvitamin D3 on human B cell differentiation," Journal of Immunology, vol. 179, no. 3, pp. 1634-1647, 2007.

[81] J. M. Lemire, J. S. Adams, R. Sakai, and S. C. Jordan, " $1 \alpha, 25$-Dihydroxyvitamin D3 suppresses proliferation and immunoglobulin production by normal human peripheral blood mononuclear cells," Journal of Clinical Investigation, vol. 74, no. 2, pp. 657-661, 1984.

[82] F. J. Barrat, D. J. Cua, A. Boonstra et al., "In vitro generation of interleukin 10-producing regulatory CD4+ T cells is induced by immunosuppressive drugs and inhibited by $\mathrm{T}$ helper type 1 (Th1)- and Th2-inducing cytokines," Journal of Experimental Medicine, vol. 195, no. 5, pp. 603-616, 2002.

[83] S. Gorman, L. A. Kuritzky, M. A. Judge et al., "Topically applied 1,25-dihydroxyvitamin D3 enhances the suppressive activity of CD4+CD25+ cells in the draining lymph nodes," Journal of Immunology, vol. 179, no. 9, pp. 6273-6283, 2007.

[84] S. Gregori, N. Giarratana, S. Smiroldo, M. Uskokovic, and L. Adorini, "A 1 $\alpha, 25$-dihydroxyvitamin D3 analog enhances regulatory T-cells and arrests autoimmune diabetes in NOD mice," Diabetes, vol. 51, no. 5, pp. 1367-1374, 2002.

[85] Z. Urry, E. Xystrakis, D. F. Richards et al., "Ligation of TLR9 induced on human IL-10-secreting Tregs by $1 \alpha, 25$-dihydroxyvitamin D3 abrogates regulatory function," Journal of Clinical Investigation, vol. 119, no. 2, pp. 387-398, 2009.

[86] R. A. Daynes, B. A. Araneo, J. Hennebold, E. Enioutina, and H. H. Mu, "Steroids as regulators of the mammalian immune response," Journal of Investigative Dermatology, vol. 105, no. 1, supplement, pp. 14S-19S, 1995.

[87] D. L. Trump, M. K. Chadha, A. Y. Sunga et al., "Vitamin $\mathrm{D}$ deficiency and insufficiency among patients with prostate cancer," British Journal of Urology International, vol. 104, no. 7, pp. 909-914, 2009.

[88] M. Urashima, T. Segawa, M. Okazaki, M. Kurihara, Y. Wada, and H. Ida, "Randomized trial of vitamin D supplementation to prevent seasonal influenza A in schoolchildren," American Journal of Clinical Nutrition, vol. 91, no. 5, pp. 1255-1260, 2010. 


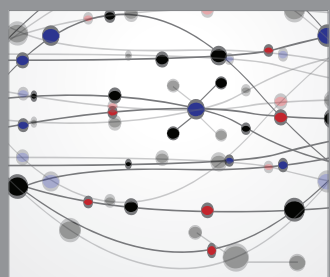

The Scientific World Journal
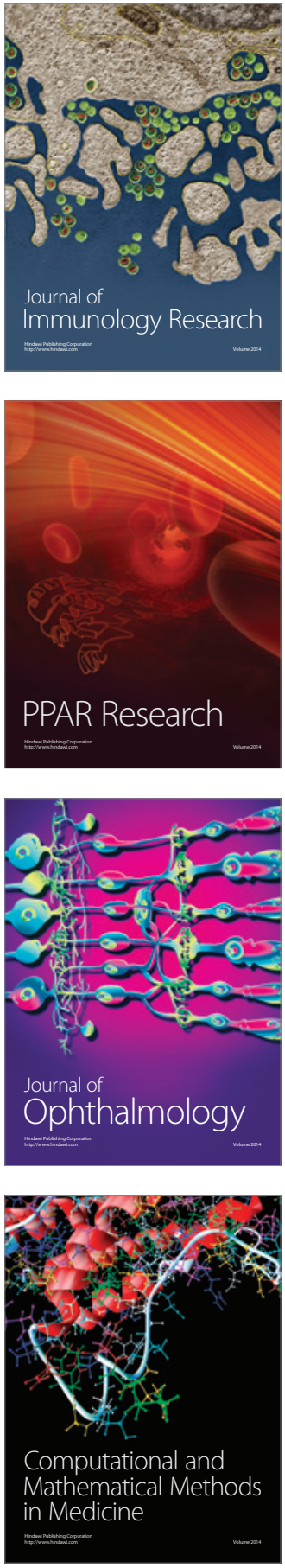

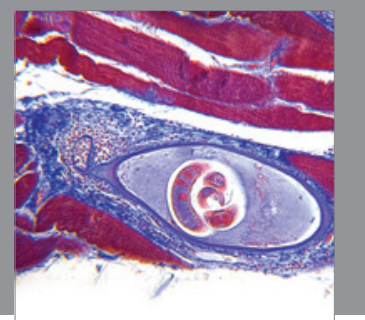

Gastroenterology

Research and Practice
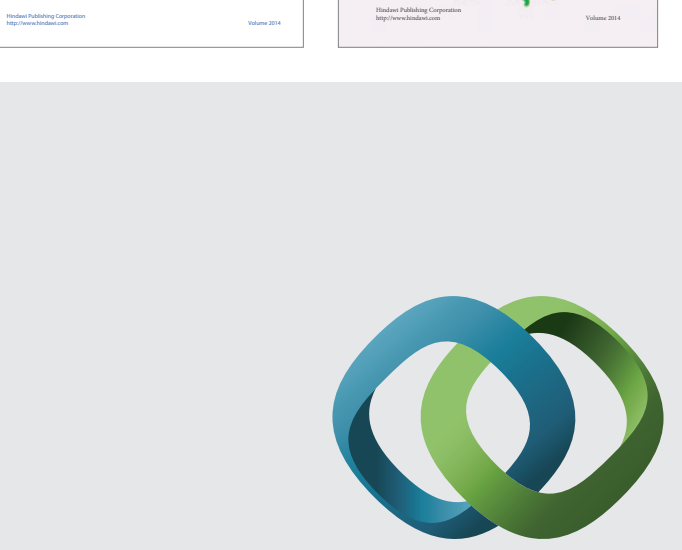

\section{Hindawi}

Submit your manuscripts at

http://www.hindawi.com
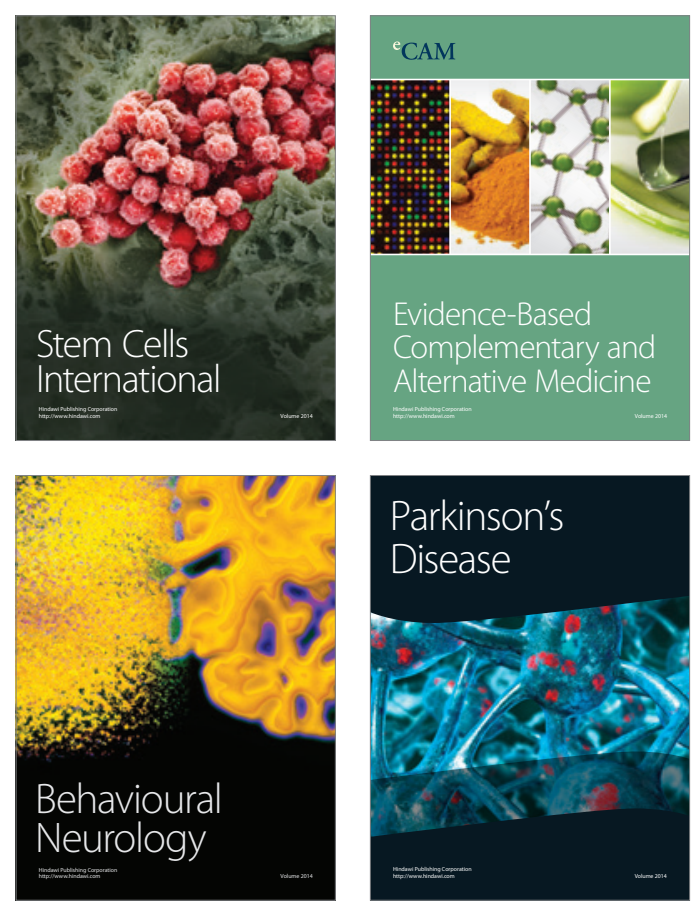

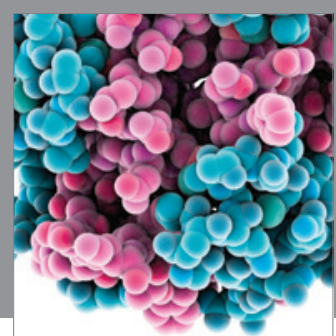

Journal of
Diabetes Research

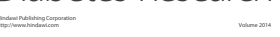

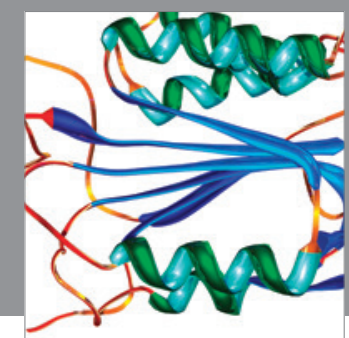

Disease Markers
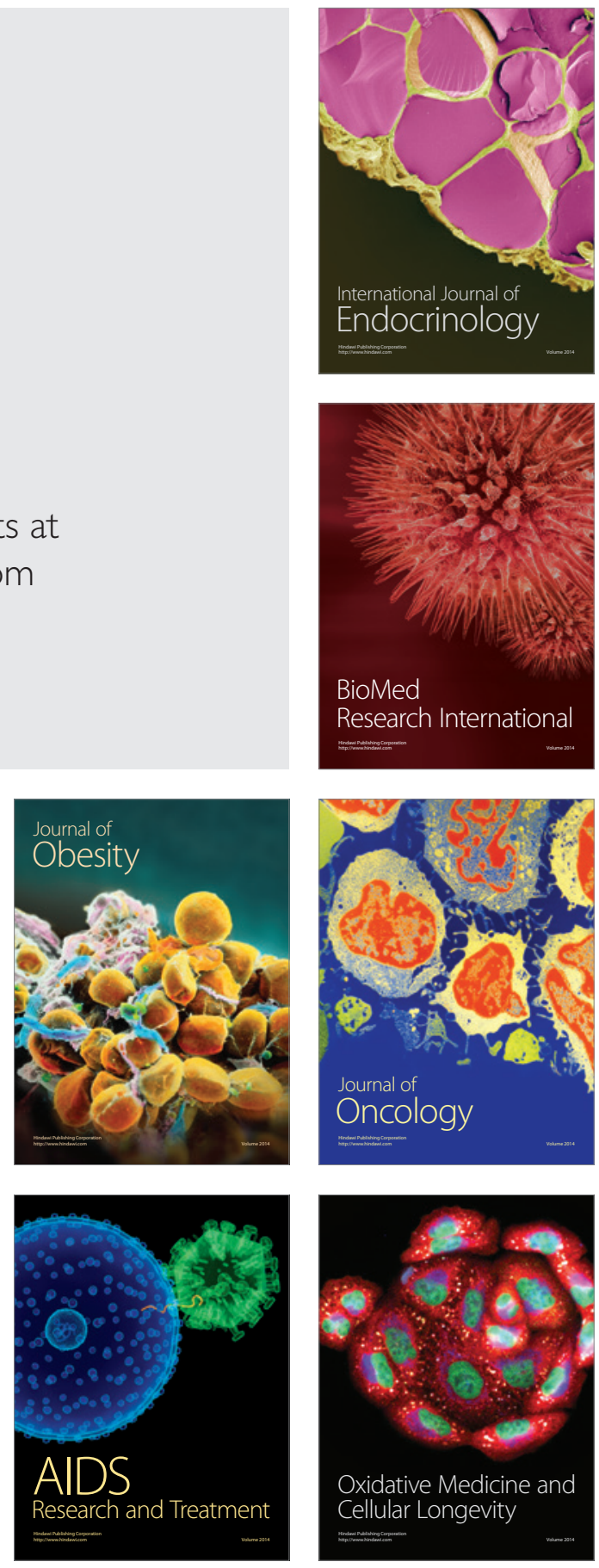